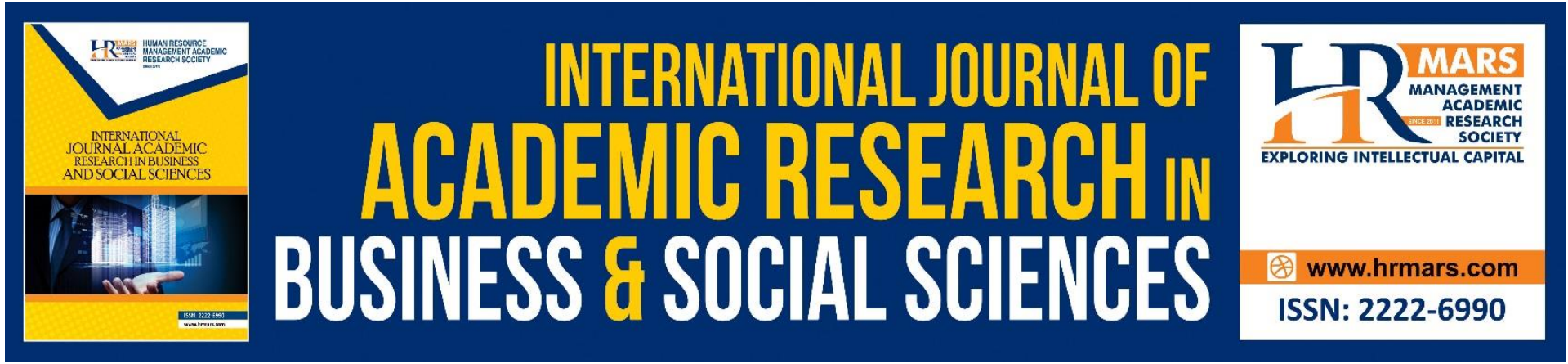

\title{
ASEAN Mass Rapid Transit Efficiency Assessment using Data Envelopment Analysis
}

Siti Sarah Januri, Norbaizura Kamarudin, Faridah Zulkipli, Farah Mardhiyah Mohd Isa, Nor Farihah Nor Azman

To Link this Article: http://dx.doi.org/10.6007/IJARBSS/v11-i8/10736

DOI:10.6007/IJARBSS/v11-i8/10736

Received: 03 June 2021, Revised: 27 June 2021, Accepted: 23 July 2021

Published Online: 02 August 2021

In-Text Citation: (Januri et al., 2021)

To Cite this Article: Januri, S. S., Kamarudin, N., Zulkipli, F., Isa, F. M. M., \& Azman, N. F. N. (2021). ASEAN Mass Rapid Transit Efficiency Assessment using Data Envelopment Analysis. International Journal of Academic Research in Business and Social Sciences, 11(8), 339-351.

Copyright: @ 2021 The Author(s)

Published by Human Resource Management Academic Research Society (www.hrmars.com)

This article is published under the Creative Commons Attribution (CC BY 4.0) license. Anyone may reproduce, distribute, translate and create derivative works of this article (for both commercial and non-commercial purposes), subject to full attribution to the original publication and authors. The full terms of this license may be seen at: http://creativecommons.org/licences/by/4.0/legalcode

Vol. 11, No. 8, 2021, Pg. 339 - 351

Full Terms \& Conditions of access and use can be found at http://hrmars.com/index.php/pages/detail/publication-ethics 


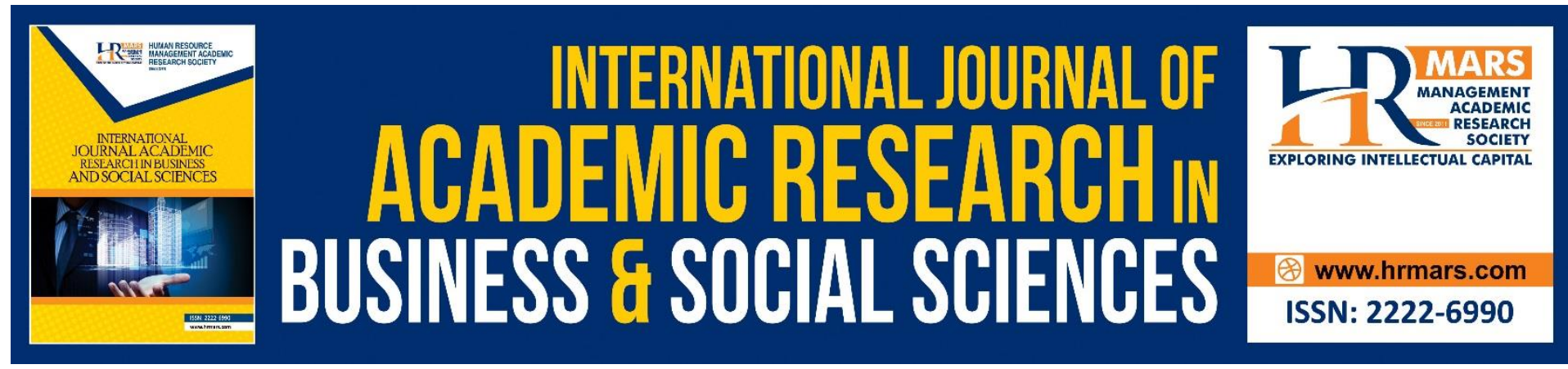

\title{
ASEAN Mass Rapid Transit Efficiency Assessment using Data Envelopment Analysis
}

\author{
${ }^{1}$ Siti Sarah Januri, ${ }^{2}$ Norbaizura Kamarudin, ${ }^{3}$ Faridah Zulkipli, \\ ${ }^{4}$ Farah Mardhiyah Mohd Isa, ${ }^{5}$ Nor Farihah Nor Azman \\ ${ }^{1,4,5}$ Faculty of Computer and Mathematical Sciences, Universiti Teknologi MARA, Negeri \\ Sembilan Branch, Seremban Campus, 70300 Seremban, Negeri Sembilan, Malaysia \\ ${ }^{2}$ Faculty of Computer and Mathematical Sciences, Universiti Teknologi MARA, 40450 Shah \\ Alam, Selangor, Malaysia, ${ }^{3}$ Faculty of Computer and Mathematical Sciences, Universiti \\ Teknologi MARA, Perak Branch, Tapah Campus, 35400 Tapah Road, Perak, MALAYSIA
}

\begin{abstract}
This paper provides a comprehensive overview of Mass Rapid Transit (MRT) efficiency in selected ASEAN countries that includes Malaysia, Philippines, Thailand, Singapore, and Indonesia. MRT is one of the popular railways public transport that has become people's alternative to move freely. However, inadequate study of MRT produces the question of whether this development is efficient or inefficient. Using Data Envelopment Analysis (DEA) to measure efficiency, this method can also identify the ways to make improvements to increase the efficiency of the MRT of ASEAN countries that areinefficient. Data obtained from the Ministry of Transport of each respective country were analyzed using Data Envelopment Analysis Online Software (DEAOS). The study identifies the efficiency score for CCR and BCC models for both input- and output-oriented. The analysis showed different results for CCR and BCC models. CCR model indicated that only Philippines and Singapore are efficient while BCC model indicated that Indonesia, Philippines, and Singapore are efficient. The improvement made for inefficient decision-making units (DMUs) only focus on BCC outputoriented model as it is more reliable to the real world since the reality have several constraints. The study reveals that inefficient DMUs which are Malaysia and Thailand must increase the number of passengers by $199.57 \%$ and $80.69 \%$ respectively to increase efficiency. The findings of this study benefit thedecision-makers in pursuance of measuring the smoothness operations of MRT using inputs and output obtained.
\end{abstract}

Keywords: Transportation, MRT, ASEAN countries, Efficiency, Data Envelopment Analysis (DEA)

\section{Introduction}

Public transport is the driver for a country to grow and become a developed country, which allows people to travel with charged fares and fixed routes and become a useful mode of transportation for people in urban and rural areas. According to Fouracre et al. (2003) public transport that has a much more bigger ability for moving people and goods efficiently and low-cost, can also be benefit in supporting city development effectively. One of the public 
transports is rail transport. The development of rail transport must be corresponding to urban development planning (Borhan et al., 2019). It will provide well-being to the residents and give comfort to them. They will use rail transport efficiently and the problem of traffic congestion can be reduced. Thus, it shows that integrated development can generate great impact on both citizens and surroundings.

Railway development can have a great impact on the economy. A study by Aziz and Masirin (2018), stated that the major impacts of transport on economic factors can be categorized as geographic specialization, scale production, competition, and land value. Acombination of capital, labor, and raw materials will lead to the good production of services and goods. In addition, large scale production with minimum cost results in a high level of efficiency in transportation. As a result, it will increase the competition and will improve the quality and modernization of transportation. The utilization of resources like land can be considered a good investment if the transport is efficient. Due to limited resources, the development of this transport should be valuable to the consumer and each rail transport runs efficiently concerning to save time, cost and can attract more users of rail transport. Moreover, the infrastructure of railway transport must be emphasized because of its contribution to economic growth in the long run.

Mass Rapid Transit (MRT) is one of rail transport system developed across the world. It is used to transport large numbers of passengers and require a short travel time. MRT appears to be designed along well-defined corridors which connects suburbs to city centers, and in most cases, they tend to reserved right-of-way for all or some of their route length (Fouracre, Dunkerley, \& Gardner, 2003). ASEAN countries that are involved in the development of MRT include Indonesia, Malaysia, Philippines, Singapore, and Thailand. The agenda of MRT is to support government programs to reduce traffic congestion and air pollution levels, reviving areas along the MRT route, and improving regional and national economies (Dahlan \& Fraszczyk, 2019). Moreover, MRT systems also had to fulfil the needs of efficient public transit systems around the world (Yeo \& He, 2009). In the direction of achieving the agenda successfully, the train schedulesmust be created to avoid congestion at train stations. A study by Ke et al (2017) also emphasizes the importance of considering energy consumption to minimize the energy cost and conserve energy.

A method called Data Envelopment Analysis (DEA) is applied to measure the efficiency of MRT. This study is important to determine which country has the highest level of efficiency. According to Mahmoudi et al (2019) shared that the applications of DEA in the transportation system have been studied in six different circumstances which are air transportation, railway transportation, maritime transportation, highway transportation, green and environmental issues, and other problems such as sustainable development, and eco-design. The most efficient MRT, that is called as "reference set" is set as an example to other countries so that the operation of MRT in ASEAN countries can be improved and sustained in the longer term. MRT is popular with the short waiting time and convenient space provided. Even though the expenses of building MRT are high and many areas need to be sacrificed, many countries take a risk to make sure that MRT is efficient in terms of operation. Every country has endless efforts to expand the railway transport sector to become more efficient and reliable towards citizens.

It is crucial to define the efficiency of this transport sector as it affects the economic growth of a country. General definition of efficiency is the ratio of work performed by a machine or in a process to the total energy expended. According to Mokhtar (2013), technical efficiency is defined as the conversion of physical inputs into outputs relative to best practice. In other 
words, given current technology, there is no wastage of inputs in producing the given quantity of output. High level of efficiency of MRT will give a good impact on the tourism sector and bring more revenue. The study of efficiency related to the transport sector has risen rapidly in recent times. Moreover, a study by Li et al. (2018) measured the technical efficiency of different railway administrations in China using DEA where the selected input were the number of employees, line length $(\mathrm{km})$, the number of locomotives and total energy consumption of locomotive (ton). Meanwhile, locomotiveworkload (hundred million $\mathrm{km}$ ) and freight turnover (hundred million ton-km) were selected as the output. Another study is about Korean subway lines by Kim et al. (2017) used the size of the transfer station, operation cost, number of operation staff and subway capacity as the inputs and the outputs were average transfer time and total number of people transferred. While, a study by Wanke and Azad (2018), the selected inputs that are considered include the route length, number of stations, as well as number of train sets.

Despite there are several applications using DEA models to evaluate efficiency in banks, hospitals, ports, and airports, yet research on railway efficiency using DEA remains scant. DEA has commonly been used to compare the efficiency of mainline railway firms. This approach is one of the most useful approaches in evaluating the transportation system and certainly useful in producing a composite measure of efficiency (Mahmoudi, Emrouznejad, ShetabBoushehri, \& Hejazi, 2019). Furthermore, surveying the efficiency of the railway transportation system will be beneficial for better integration and performance of this system.

\section{Methodology}

Railway transportation is built not to increase the land transportation, but this development is aiming to improve the existence of the system and service provided. Supported by Barnum et al. (2007), the most common method to measure efficiency to improve the service or performance of rail transport is using the DEA method. The DEA approach is used to measure its efficiency of the performance of the sub units. The DEA approach is used the countries as decision-making units (DMUs). The DEA, was first introduced by Charnes, Cooper and Rhodes in 1978 and they were extended the Farrell's (1957) idea of estimatingtechnical efficiency with respect to a production frontier (Charnes et al., 1978). According to Vincová (2005), it is a linear programming model used to measure technical efficiency, assuming no random mistakes. Efficient firms are those that produce a certain amount of or more outputs while spending a given number of inputs, or use the same amount of or less inputs to produce a given number of outputs, when compared with other firms in the test group. As stated by Wanke et al (2018), despite the limited variations in input or output vectors to improve performance, DEA remains the popular technique in railway studies.

In this study, several inputs and outputs have been used to measure Asian railways efficiency. The input variables included the number of railway locomotives ready for operation, total railway route length (in $\mathrm{km}$ ), and the number of freight wagons. Meanwhile, since some countries like Malaysia and Philippines only have one line inoperation, there are no transfers of people. So, the output used for this study is only the total number of passengers riding the MRT. The objective of this study is to determine the technical efficiency and service effectiveness of major passenger stations by using DEA method. The output variable is flexible to changes as the number of passengers is controllable. Therefore, this study adopts the output-oriented model that calculates the technical efficiency by changing the output. Nevertheless, input-oriented model is also used to compare the result of the analysis. 
The input-output indicators of theMRT of ASEAN countries include the main output of the study that is the number of passengers which is influenced by the route length, number of stations and number of train sets which are the inputs (Yangdong et al, 2020). The inputs are the route length in kilometer, number of stations and number of train sets. Meanwhile, there is only one output which is the number of passengers. The suitable method selected is supported by Vincová (2005) that is the DEA to measure the efficiency.

The description of variables used in this study is illustrated in Table 1. Route length is the sum of length in kilometer of the routes in MRT railways that are ready for operation.Number of stations refers to the stations that are ready for operation, excluding the ones that are still under construction or in planning. Number of train sets is the sets of train used by each country consist of four-car train or a six-car train. For the output, the number of passengers refers to the total number of passengers in 2019.

Table 1: Descriptions of variables

\begin{tabular}{|c|c|c|}
\hline Variable & Type of variable & Description \\
\hline Route length & Input & $\begin{array}{l}\text { Total length of the route ready for operation in } \\
\text { kilometers }\end{array}$ \\
\hline Number of stations & Input & Number of stations ready for operation \\
\hline Number of train sets & Input & Number of trains sets ready for operation \\
\hline Number of passengers & Output & Total number of passengers in 2019 \\
\hline
\end{tabular}

\section{DEA Model}

The basic DEA models are CCR model (Charnes, Cooper, and Rhodes) and BCC model (Banker, Charnes, and Cooper) which were named after the authors that came up with this model. CCR model calculates the overall technical efficiency (TE) which assumes constant return to scale (CRS). However, Kocisove (2015) stated that this assumption of CRS can be accepted if the DMUs operate under their optimal size condition or in simpler words, a perfect competition. But in the real world, imperfect competition happens whereby financial constraints, control steps and other factors will cause the DMUs to not operate in optimal state. Then, in 1984, Banker et al. (1984) developed a new model which is modified from the CCR model to overcome this problem by relaxing the restriction of CRS to account variable return to scale (VRS) technology. They did this by adding a convexity constraint to the CCR model and referred to it as the BCC model. This new model is to measure pure technical efficiency (PTE) and is more realistic because it takes into consideration of the constraints.

The meaning of technical efficiency is to optimize inputs based on the output given. According to Sexton (1986), to measure the relative efficiency of the service, the ratio of its total weighted output to its total weighted input was calculated. DEA allows decision-making unit to select any weight to each input and outputs based on reasonable conditions. Two conditions will be applied to select weight are weight should not be negative and universal. The non-negative value indicates that the value should be more than zero. Meanwhile, universality indicates that any DMU should be able to apply a similar set of weights to estimate its ratio and the ratio must not exceed one. In DEA models, each DMU utilizes number of different inputs to produce number of different outputs to evaluate number of productive units, DMUs. A unit with an efficiency score of 1 (100 percent) is considered as 
efficient. Otherwise, the unit is inefficient. Both CCR and BCC model are divided into two categories which are input-oriented and output-oriented.

Input-oriented

Objective function

Min $\theta$

Subject to

Constraint

$\sum_{j=1}^{n} \lambda_{j} x_{i j}=\theta x_{i 0}$

$\sum_{j=1}^{n} \lambda_{j} y_{r j}=\theta y_{r 0}$

$\lambda_{j} \geq 0$

0

Convexity constraint

$\sum_{j=1}^{n} \lambda_{j}=1$

1

\section{Output-oriented}

$\operatorname{Max} \phi$

$$
\begin{aligned}
& \sum_{j=1}^{n} \lambda_{j} x_{i j} \leq \\
& \sum_{j=1}^{n} \lambda_{j} y_{r j} \geq \\
& \lambda_{j} \geq
\end{aligned}
$$

$$
\sum_{j=1}^{n} \lambda_{j}=
$$

\section{Where}

$\theta=$ input - oriented efficiency score;

$\phi=$ output - oriented efficiency score;

$i=1, \ldots m$ (inputs);

$r=1, \ldots, s$ (outputs)

$j=1, \ldots, n$ (DMUs);

$x_{i j}=$ amount of input $i$ by $\mathrm{DMU}_{\mathrm{j}}$;

$y_{r j}=$ amount of output $r$ by $\mathrm{DMU}_{\mathrm{j}}$;

$\lambda_{j}=$ weight given to input and output.

Equation 1 is the objective function which should be minimized or maximized depending on the analysis whether it is input- or output-oriented. Input constraint 2 is formulated by the summation of the sum product of each input values $i(i=1, \ldots, m)$ and its weight should be less than or equal to the amount used by $D M U_{j}$, depending on the method of analysis. For each output $r(r=1, \ldots, s)$, the summation of the sum of each output values and its weight as in Equation should be greater than or equal to the amountused by $D M U_{j}$ depending on whether input- or output- oriented analysis is applied. Each of the lambdas (weight) should be non-negative as stated in the constraint 4 where $j=1,2, \ldots 5$ since there are five DMUs in this study which are the MRT of the chosen ASEAN countries. The convexity constraint in Equation 5 is only added in the BCC model. This constraint is required as it applies the variable return to scale assumption technology developed by Banker et al. (1984).

In input-oriented, DMUs is rated inefficient if $\theta$ obtained a score of less than $1(\theta<1)$. If $\theta=$ 1 , then the DMU currently rated is efficient. For the output-oriented method, if the optimal solution gives $\phi=1$ for all such composite MRT, then the MRT at hand is efficient. On the other hand, $\phi>1$ proves that the MRT currently rated is inefficient. Since the optimal solution to the both CCR and BCC model can only be between 0 and $1\left(0 \leq \theta_{0}<1\right)$, the values of the objective functions must be inverted, making it $\theta=1 / \phi$. 


\section{Strategies For Improving Efficiency}

The main advantage of using DEA approach is that this method also enables us to discoverhow a productive unit should change its behavior to become more efficient. So, several improvements should be made to increase the level of efficiency. Such strategies include the application of radial movement, reference sets and slacks to help in increasing the efficiency values.

\section{Radial Movement and Reference Sets}

Based on Lee at al. (2016), radial movement is defined as the movement of inefficient DMUs has to take in order to be located on the frontier. Reference sets will help inefficientDMUs to imitate efficient DMUs. The selection of efficient DMUs as the best practice is based on the highest peer weight of efficient DMUs. In this study, the improved values onlyfocus on output as it is controllable, and it is not necessary to modify the value of inputs. Therefore, for an MRT to be efficient, output resources should be modified to improve thelevel of efficiency. Radial movement can be calculated as shown in Equation 6.

$$
\text { Radial movement }=\text { Target value }- \text { Actual value }
$$

Actual values are being subtracted from target values to obtain the radial movement. Hence, itshows the differences between actual values and target values for the number of outputs. Next, percent change of the radial movement also matters in order to illustrate a better viewin terms of percentage of how the amount of outputs should be changed to improve the performance of MRT. The formulation of percent change can be computed using Equation 7.

$$
\text { Percent change }(\%)=\frac{\text { Radial movement }}{\text { Actual value }} \times 100 \%
$$

Percent change explains the behavior of the changes of outputs that should be increased from the actual values in order to increase the level of efficiency. Therefore, it helps the decisionmakers to identify the improvement that needs to be accomplished to improve the performance of MRT for each DMU.

\section{Slack Treatment}

Slacks is the additional movement that an inefficient DMU has to take in order to become efficient (Lee et al., 2016). The input-oriented model suggests that productive units must lower its inputs to become efficient. On the contrary, to attain efficiency in the outputoriented model, productive units must increase their outputs.

To increase efficiency for both input and output version applied in this study, additional variables $s_{i}^{-}$and $s_{r}^{+}$called slacks are added to the inefficient DMU. This process is done in a two-stage calculation. First is the efficiency score obtained from Equation 1. Second step is the slack model with the efficiency score fixed. The slack models of the input- and outputoriented model are shown below.

\section{Input-oriented}

$\sum_{r=1}^{s} s_{r}^{+} \underset{i=1}{\operatorname{Max} \sum_{i=1}^{m} s_{i}^{-}+\sum_{r=1}^{s} s_{r}^{+}}$

\section{Output-oriented}

$\operatorname{Max} \sum_{i=1}^{m} s_{i}^{-}+$ 
Subject to

$$
\sum_{j=1}^{n} \lambda_{j} x_{i j}+s_{i}^{-}=\theta^{*} x_{i 0}
$$

$\theta^{*} x_{i 0}$

$\sum_{j=1}^{n} \lambda_{j} y_{i j}-s_{r}^{+}=\theta^{*} y_{r 0}$

$\phi^{*} y_{r 0}$

(10)

$\lambda_{j}, s_{i}^{-}, s_{r}^{+} \geq 0$

0

$$
\sum_{j=1}^{n} \lambda_{j}=1
$$

1
Subject to

$$
\begin{gathered}
\sum_{j=1}^{n} \lambda_{j} x_{i j}+s_{i}^{-}= \\
\sum_{j=1}^{n} \lambda_{j} x_{i j}-s_{r}^{+}= \\
\lambda_{j}, s_{i}^{-}, s_{r}^{+} \geq \\
\sum_{j=1}^{n} \lambda_{j}=
\end{gathered}
$$

Equation 8 is the objective function that maximizes the summation of slacks in inputs and outputs. The only difference of the two equations is the right-hand side value of the input and output constraint. In Equation 9 of the input-oriented method, the weighted input added with the input slacks is equal to the input values multiplied with the efficiency score $\theta$. While in Equation 10, the weighted outputs minus the output slacks is equal to the output values multiplied with the efficiency score $\phi$ of the output-oriented method, before inverted. Other requirements that includes non-negativity is displayed in Equation 11 where $\lambda_{j}, s_{i}^{-}$, and $s_{r}^{+}$ should never be below zero. Convexity constraint similar to Equation 5 is added if the slacktreatment is applied to the BCC model, otherwise excluded.

\section{Results and Discussions}

The efficiency of MRT among ASEAN countries were analyzed by using Data Envelopment Analysis Online Software (DEAOS). There are five DMUs which are Indonesia, Malaysia, Philippines, Singapore, and Thailand. Total number of passengers in 2019 is assigned as output, while the number of stations, number of train sets and route length (in kilometers) as inputs and is illustrated in Table 2.

Table 2: Input and output values for each country

\begin{tabular}{|l|l|l|l|l|}
\hline \multirow{2}{*}{ Country } & \multicolumn{3}{|c|}{ Inputs } & Output \\
\cline { 2 - 5 } & $\begin{array}{l}\text { Route length } \\
(\mathrm{km})\end{array}$ & $\begin{array}{l}\text { Number of } \\
\text { stations }\end{array}$ & Number of train sets & $\begin{array}{c}\text { Number of } \\
\text { passengers }\end{array}$ \\
\hline Indonesia & $\mathbf{1 5 . 7}$ & $\mathbf{1 3}$ & $\mathbf{1 6}$ & $\mathbf{2 4 , 6 2 1 , 4 6 7}$ \\
\hline Malaysia & 51 & 31 & 58 & $63,952,805$ \\
\hline Philippines & 16.9 & 13 & 19 & $96,932,972$ \\
\hline Singapore & $\mathbf{2 0 1 . 9}$ & $\mathbf{1 2 2}$ & $\mathbf{4 8 8}$ & $\mathbf{1 , 2 3 5 , 1 6 0 , 0 0 0}$ \\
\hline Thailand & $\mathbf{7 0 . 6}$ & 53 & $\mathbf{7 5}$ & $128,864,900$ \\
\hline
\end{tabular}

MRT in Indonesia consists of 13 stations along the $15.7 \mathrm{~km}$ route and 16 train sets are used to carry $24,621,467$ passengers in 2019 . On the other hand, Singapore has $201.9 \mathrm{~km}$ MRT route that connects all parts of Singapore from North to Southand East to West. With 122 stations and 488 train sets, a total of 1,235,160,000 passengersrode the MRT in 2019.

\section{Efficiency score for CCR model and BCC model}

A DMU can be characterized as efficient as it reaches 1 . The efficiency value for CCR model remains the same for both input- and output-oriented. The reason is that under the CRS technology assumption, the production frontier is linear making the output increases at the same rate as inputs are increased. It indicates that Philippines and Singapore are considered 
as efficient DMUs, meanwhile, Indonesia, Malaysia, and Thailand can be categorized as inefficient DMUs as the value of the efficiency score is less than 1 as shown in Table 3. While, $\mathrm{BCC}$ model varies in their efficiency rating for both input-output-oriented. This is because the output changes at a rate that is different than that of the inputs as a variable return to scale (VRS). As a result, the MRT in Indonesia is classified as efficient as Philippines andSingapore. But Malaysia and Thailand are still categorized as inefficient DMUs.

In general, the CCR model produces more inefficient DMUs compared to the BCC model.This is because the BCC model is more appropriate in real life context compared to the CCR model, as it takes into consideration of factors in the real world that cause the DMUsto not operate in the optimal state. It can be confirmed that theresult showed more inefficient DMUs under CRS assumption. Similar result obtained in this study, DEA output-oriented model of MRT in ASEAN countries also resulted with more inefficient DMUs under CRS assumption, which returned Indonesia, Malaysia, and Thailand as inefficient DMUs. Imperfect competition in the real world has caused the MRT to have problems operating in an optimal state due to financial constraints, government regulations, control steps, andother factors. That is why BCC model which is under VRS assumption is more suitable to measure the performance of MRT in reality.

Table 3: Efficiency rate for CCR and BCC model

\begin{tabular}{|l|l|l|l|l|}
\hline \multicolumn{3}{|c|}{ Efficiency rate for CCR model } & \multicolumn{2}{c|}{ Efficiency rate for BCC model } \\
\hline DMU & $\begin{array}{l}\text { Input- } \\
\text { oriented }\end{array}$ & Output-oriented & Input-oriented & Output-oriented \\
\hline Indonesia & 0.30 & 0.30 & 1.00 & 1.00 \\
\hline Malaysia & 0.26 & 0.26 & 0.42 & 0.33 \\
\hline Philippines & 1.00 & 1.00 & 1.00 & 1.00 \\
\hline Singapore & 1.00 & 1.00 & 1.00 & 1.00 \\
\hline Thailand & 0.34 & 0.34 & 0.43 & 0.55 \\
\hline
\end{tabular}

\section{Improvements to Increase the Level of Efficiency using Radial Movement}

Radial movement is defined as the movement of the inefficient DMUs must take in orderto improve the efficiency score. To improve the performance of inefficient MRT, output-oriented for both CCR and BCC models are taken into consideration to make comparison. For outputoriented version, the proportional of outputs must increase without changing the values of input. Hence, the study only focuses on the output as it is not necessary to adjust the value of inputs. The route length, number of stations, and number of train sets are unable to be changed asit incurs a high cost to build all the inputs and access is restricted to many passengers. Therefore, the improvement to increase the performance of MRT should be focused only on the number of passengers as it is controllable. Table 4 shows the improved values forinefficient DMUs of CCR output-oriented model. 
Table 4: Improved values for inefficient DMUs of CCR output-oriented model

\begin{tabular}{|c|c|c|c|c|c|}
\hline \multirow[t]{2}{*}{ DMU } & & \multicolumn{3}{|c|}{$\begin{array}{l}\text { Input } \\
\text { s }\end{array}$} & \multirow{2}{*}{$\begin{array}{l}\text { Output } \\
\text { Number of } \\
\text { passengers }\end{array}$} \\
\hline & & Route length (km) & $\begin{array}{l}\text { Number of } \\
\text { stations }\end{array}$ & $\begin{array}{l}\text { Number of } \\
\text { train sets }\end{array}$ & \\
\hline \multirow{4}{*}{ Indonesia } & Actual & 15.7 & 13 & 16 & 24621467 \\
\hline & Target & 15.7 & 13 & 16 & 81627766 \\
\hline & $\begin{array}{l}\text { Radial } \\
\text { movement }\end{array}$ & 0 & 0 & 0 & 57006299 \\
\hline & $\begin{array}{l}\text { Percent } \\
\text { change }\end{array}$ & $0 \%$ & $0 \%$ & $0 \%$ & $231.53 \%$ \\
\hline \multirow{4}{*}{ Malaysia } & Actual & 51 & 31 & 58 & 63952805 \\
\hline & Target & 51 & 31 & 58 & 244487255 \\
\hline & $\begin{array}{l}\text { Radial } \\
\text { movement }\end{array}$ & 0 & 0 & 0 & 180534450 \\
\hline & $\begin{array}{l}\text { Percent } \\
\text { change }\end{array}$ & 0 & 0 & 0 & $282.29 \%$ \\
\hline \multirow{4}{*}{ Thailand } & Actual & 70.6 & 53 & 75 & 128864900 \\
\hline & Target & 70.6 & 53 & 75 & 382630153 \\
\hline & $\begin{array}{l}\text { Radial } \\
\text { movement }\end{array}$ & 0 & 0 & 0 & 253765253 \\
\hline & $\begin{array}{l}\text { Percent } \\
\text { change }\end{array}$ & $0 \%$ & $0 \%$ & $0 \%$ & $196.92 \%$ \\
\hline
\end{tabular}

The number of passengers in Indonesia must be increased by $57,006,299$ to obtain the optimal solution, making it a total of $81,627,766$ passengers. It is followed by the changing number of passengers in Malaysia by $180,534,450$, making it a total of $244,487,255$ passengers. For Thailand, the improvement by $253,765,253$ passengers must be made to gain an increase in the efficiency score and creating the targetof $382,630,153$ passengers. The percent change for the radial movement for Indonesia, Malaysia and Thailand are $231.5 \%, 282.29 \%$ and $196.92 \%$ respectively. Notice that the projected values are extremely high which are almost three times of the actual value. 
Table 5: Improved values for inefficient DMUs of BCC output-oriented model

\begin{tabular}{|c|l|l|l|l|c|}
\hline \multirow{2}{*}{ DMU } & \multicolumn{4}{|c|}{ Inputs } & Output \\
\cline { 3 - 6 } & Route length (km) & $\begin{array}{l}\text { Number of } \\
\text { stations }\end{array}$ & $\begin{array}{c}\text { Number of } \\
\text { train sets }\end{array}$ & $\begin{array}{c}\text { Number of } \\
\text { passengers }\end{array}$ \\
\hline \multirow{5}{*}{ Malaysia } & Actual & 51 & 31 & 58 & $63,952,805$ \\
\cline { 2 - 6 } & Target & 51 & 31 & 58 & $191,582,981$ \\
\cline { 2 - 6 } & $\begin{array}{l}\text { Radial } \\
\text { movement }\end{array}$ & 0 & 0 & 0 & $127,630,176$ \\
\cline { 2 - 6 } & $\begin{array}{c}\text { Percent } \\
\text { change }\end{array}$ & $0 \%$ & $0 \%$ & $0 \%$ & $199.57 \%$ \\
\hline \multirow{3}{*}{ Thailand } & Actual & 70.6 & 53 & 75 & $128,864,900$ \\
\cline { 2 - 6 } & Target & 70.6 & 53 & 75 & $103,975,777$ \\
\cline { 2 - 6 } & $\begin{array}{l}\text { Radial } \\
\text { movement }\end{array}$ & 0 & 0 & 0 & $80.69 \%$ \\
\cline { 2 - 6 } & $\begin{array}{l}\text { Percent } \\
\text { change }\end{array}$ & $0 \%$ & $0 \%$ & $0 \%$ & \\
\hline
\end{tabular}

In comparison to the BCC model, there are two DMUs involved to improve the number of passengers to enhance the performance of MRT. Table 5 presents the improved values for inefficient DMUs of BCC output-oriented model. For Malaysia, the optimal solution can be achieved by a radial movement of $127,630,176$ passengers, increasing the output toa total of $191,582,981$ passengers. There should be a $199.57 \%$ increment of passengers that needs to be increased toward increasing the level of efficiency. Meanwhile, the optimal solution for Thailand can be achieved by increasing the number of passengers by $103,975,577$, amounting to $232,840,677$ passengers. So, $80.69 \%$ addition of passengers is needed to increase to improve the efficiency level in Thailand.

The projected figures of number of passengers in BCC output-oriented are slightly lower than that of CCR output-oriented. Therefore, it is more achievable, considering the constraints of operating in the imperfect competition. Imperfect competition happens due to many constraints such as regulations that disallow the MRT to operate 24 hours a day. Also, some passengers that prefer to use other transport instead of the MRT contribute to the low number of passengers, hence reducing the MRT efficiency.

\section{Conclusions and Future Recommendations}

Applications of DEA are used in a wide range of contexts such as transportation, banking, healthcare, education, bench marking and many more. This study aims to provide a satisfactory answer to determine the efficiency of MRT of five ASEAN countries by applying DEA approach. From the analysis, the efficiency score examined using input- and outputoriented CCR resulted with MRT of only Philippines and Singapore being efficient. Meanwhile, the results for BCC model for both input- and output-oriented indicated that Indonesia, Philippines, and Singapore attained an efficiency score of 1 . Malaysia and Thailand are considered inefficient as they obtained a score of less than 1 . The study presents a better understanding when improvements can be made to improve the efficiency score. In general, to increase the efficiency score, it is necessary to increase the amount of output for the output-oriented model.

The study focuses on the BCC output-oriented model as is more realistic to the real world. The study reveals that inefficient DMUs which are Malaysia and Thailand must increase the 
number of passengers by $199.57 \%$ and $80.69 \%$, respectively. The results obtained are beneficial to managers to define the performance of MRT as it indicates the quality of railway transportfor every country participated. On the other hand, the findings of this study also benefit the decision-makers in pursuance of measuring the smoothness operations of MRT using inputs and output obtained. Therefore, Malaysia and Thailand can improve their MRT facility to be better by mending the number of outputs. This research is, in effect, investigational, and its findings are far from final but instead, itrepresents a basis for further research and analysis. So, this study encourages other researchers to observe the continuous development of MRT after implementing efficiency analysis.

\section{Corresponding Author}

Dr Norbaizura Kamarudin

Faculty of Computer and Mathematical Sciences Universiti Teknologi MARA, Shah Alam 40450 Selangor, MALAYSIA

Email: norbaizura@tmsk.uitm.edu.my

\section{References}

Abd Aziz, S., Kasim, R., \& Mohd Masirin, M. I. (2018). Railway Development and the Impact to Malaysian Economy. Journal of Advanced Research in Dynamical and Control Systems, 10(6), 272-280.

Banker, R. D., Charnes, A., \& Cooper, W. W. (1984). Some Models for Estimating Technical and Scale Inefficiencies in Data Envelopment Analysis. MANAGEMENT SCIENCE, 30(9), 1078-1092.

Barnum, D. T., Mcneil, S., \& Hart, J. (2007). Comparing the Efficiency of Public Transportation Subunits Using Data Envelopment Analysis. Journal of Public Transportation, (June). https://doi.org/10.5038/2375-0901.10.2.1

Borhan, M. N., Ibrahim, A. N. H., Syamsunur, D., \& Rahmat, R. A. (2019). Why Public Bus is a Less Attractive Mode of Transport : A Case Study of Putrajaya, Malaysia. Periodica Polytechnica Transportation Engineering , 47(1), 82-90. https://doi.org/10.3311/PPtr.9228

Charnes, A., Cooper, W. W., \& Rhodes, E. (1978). Measuring the efficiency of decision making units. European Journal of Operational Research, 2, 429-444.

Dahlan, A. F., \& Fraszczyk, A. (2019). Public Perceptions of a New MRT Service : a Pre-launch Study in Jakarta. Urban Rail Transit, 5(4), 278-288.

Fouracre, P., Dunkerley, C., \& Gardner, G. (2003). Mass rapid transit systems for cities in the developing world. Transport Reviews: A Transnational Transdisciplinary Journal, 23(3), 299-310. https://doi.org/10.1080/0144164032000083095

Ke, B.-R., Lian, K.-L., Ke, Y.-L., Huang, T.-H., \& Mirwandhana, M. R. (2017). Control Strategies for Improving Energy Efficiency of Train Operation and Reducing DC Traction Peak Power in Mass Rapid Transit System. 2017-ESC-0119, 1-9.

Kočišová, K. (2013). Technical efficiency of top 50 world banks. Journal of Applied Economic Sciences, 8(3), 311-322.

Kim, C., Kim, S. W., Kang, H. J., \& Song, S.-M. (2017). What Makes Urban Transportation Efficient ? Evidence from Subway Transfer Stations in Korea. Sustainability, 9(2054), 118. https://doi.org/10.3390/su9112054

Lee, B., Won, D., Park, J.-H., Kwon, L., Moon, Y.-H., \& Kim, H.-J. (2016). Patent-Enhancing Strategies by Industry in Korea Using a Data Envelopment Analysis. Sustainability, 
8(901), 1-17. https://doi.org/10.3390/su8090901

Li, Y., Li, X., \& Khalid, M. A. (2018). Measuring technical efficiency of Chinese railway administrations by DEA method. Journal of Interdisciplinary Mathematics, 21(4), 825836. https://doi.org/10.1080/09720502.2018.1475062

Mahmoudi, R., Emrouznejad, A., Shetab-Boushehri, S.-N., \& Hejazi, S. R. (2019). The origins, development and future directions of Data Envelopment Analysis approach in transportation systems. Socio-Economic Planning Sciences.

Mokhtar, K. (2013). Technical Efficiency of Container Terminal Operations : a Dea Approach. Journal of Operations and Supply Chain Management, 6(2), 1-19.

https://doi.org/10.12660/joscmv6n2p1-19

Sexton, T. R. (1986). The Methodology of Data Envelopment Analysis, (52).

Vincová, I. K. (2005). Using DEA models to measure efficiency. Theory, XIII(8).

Wanke, P., \& Azad, M. A. K. (2018). Efficiency in Asian railways: a comparison between data envelopment analysis approaches. Transportation Planning and Technology, 41(6), 573-599. https://doi.org/10.1080/03081060.2018.1488928

Wanke, P., Chen, Z., Liu, W., Antunes, J. J. M., \& Kalam, A. (2018). Investigating the drivers of railway performance : Evidence from selected Asian countries. Habitat International, (April).

Yangdong, C., Wang, Z., \& Jinzheng, R. (2020). Efficiency Analysis of the Input for WaterSaving Agriculture in China. Water, 12(207), 1-16. https://doi.org/10.3390/w12010207

Yeo, S. K., \& He, Y. (2009). Commuter characteristics in mass rapid transit stations in Singapore. Fire Safety Journal, 44, 183-191.

https://doi.org/10.1016/j.firesaf.2008.05.008 